\title{
Muscular strength of adult Special Olympians by country economic status
}

\author{
Sara Santarossa ${ }^{1}$, Viviene A. Temple ${ }^{2}$, Pauli Rintala ${ }^{3}$, Meghann Lloyd ${ }^{4}$, Brooke DeMarco ${ }^{5}$, \\ and John T. Foley ${ }^{5}$
}

${ }^{1}$ Department of Kinesiology, University of Windsor, Canada, ${ }^{2}$ School of Exercise Science, Physical and Health Education, University of Victoria, Canada; ${ }^{3}$ Department of Sport Sciences, University of Jyväskylä, Finland; ${ }^{4}$ Faculty of Health Sciences, University of Ontario Institute of Technology, Canada; and ${ }^{5}$ Phys ical Educatiion Department, State University of New York College at Cortland, USA

There is a strong relationship between economic prosperity and health as well as between muscle strength and health
(morbidity and mortality). However, very little research has concomitantly examined economic prosperity and mus-
cular strength in the general population, and no studies have simultaneously examined these factors in a population
of adults with intellectual disabilities. This study examined grip strength among adult Special Olympics participants
by country economic status. A total of 12,132 (men $=65 \%$ ) right and left hand grip strength records were available
from the Special Olympics International (SOI) FUNFitness database. The 127 countries within the SOI dataset were
grouped by economy according to The World Bank's gross national income per capita as: low-income countries
$(\mathrm{n}=11)$, lower middle-income countries ( $n=27)$, upper middle-income countries $(n=38)$, and high-income count-
ries $(n=51)$. There was a significant overall effect of country economic status for both males and females for right
and left hand grip strength. Although the grip strength of both men and women did not differ between low-income
and low-middle income countries, the general trend was to observe greater grip strength with increased economic
prosperity among both men and women. However, to advance our knowledge of the importance of muscle strength
for persons with intellectual disabilities, research linking grip strength to health outcomes, functional status, and
successful participation activities of daily living is needed.

Keywords: fitness, intellectual disability, health, strength

\section{Introduction}

Measured physical fitness is an important predictor of mortality and morbidity (Kodama et al., 2009; Ortega, Silventoinen, Tynelius, \& Rasmussen, 2012). Growing evidence suggests that persons with higher levels of physical fitness have a reduced risk of various chronic conditions (i.e., Type 2 diabetes, stroke, coronary heart disease), and are more physically independent in later life (Brandon, Boyette, Gaasch, \& Lloyd, 2000; Brill, Macera, Davis, Blair, \& Gordon, 2000; Caruso, Silliman, Demissie, Greenfield, \& Wagner, 2000). Research has shown that people with an intellectual disability have generally low physical fitness levels and are consistently less physically fit than their peers without a disability (Fernhall \& Pitetti, 2001; Pitetti, Yarmer, \& Fernhall, 2001; Pitetti \& Yarmer, 2002). Although individuals with disabilities are beginning to have a life expectancy closer to that of the general population, their ageing process usually coincides with poor health, high rates of multi-morbidity, and frailty at an extremely young age (Evenhuis, Hermans, Hilgenkamp, Bastiaanse, \& Echteld, 2012). Along with poor physical fitness levels, this may increase the likelihood that persons with intellectual disability will have greater difficulty maintaining their ability to work, participate in their community, and perform self-care activities (Graham \& Reid, 2000; Special Olympics Report, 2001), thus resulting in a poorer quality of life.

Muscular strength is an important component of health-related fitness (Faigenbaum, 2016). In particular, higher muscular strength is associated with decreased mortality from all-causes, from cardiovascular disease, and some forms of cancer (Gale, Martyn, Cooper, \& Sayer, 2007); as well as lower rates of functional limitations in upper limbs (Kuh et al., 2005). Muscular strength can be measured in a variety of ways (Guadalupe-Grau et al., 2015), however the hand grip strength test is widely used, easy to administer, valid and reliable measure of muscular strength (Cuesta-Vargas \& Hilgenkamp, 2015). 
Importantly, reduced muscle strength, as measured by hand grip strength, is associated with an increased risk of mortality (Gale et al., 2007; Newman et al., 2006; Ortega et al., 2012) and it is a strong predictor of morbidity and life expectancy (Metter, Talbot, Schrager, $\&$ Conwit, 2002). More specifically, poor hand grip strength has been used as a predictive factor for health concerns such as sarcopenia, nutritional status, frailty, and low physical fitness in both the general population (Leong et al., 2015; Roberts et al., 2011) and in persons with intellectual disability (Bastiaanse, Hilgenkamp, Echteld, \& Evenhuis, 2012; Evenhuis et al., 2012).

Improving muscular strength has been identified as a health promotion need of people with intellectual disabilities (Taggart \& Cousins, 2013), however data on the strength of persons with an intellectual disability is limited. Of the little research done in this area, a study of 1050 adults with an intellectual disability (Hilgenkamp, van Wijck, \& Evenhuis, 2012) and a study of 848 older adults with intellectual disabilities (Evenhuis et al., 2012), suggest that adults with an intellectual disability have poor grip strength. Furthermore, similar to the general population (Kuh et al., 2005), adult females with intellectual disabilities have been found to have lower grip strength than their male counterparts (Cuesta-Vargas \& Hilgenkamp, 2015).

It is known that there is a strong relationship between economic prosperity and health in the general population (Ruger, Jamison, \& Bloom, 2001). Specifically, higher-income countries have been found to have higher levels of physical fitness, when compared with lower-income countries (Theou et al., 2013). In terms of muscular strength, The Prospective UrbanRural Epidemiology (PURE) study (Leong et al., 2015), a large, longitudinal population study done in 17 countries of varying incomes and sociocultural settings, found that the association between grip strength and a variety of chronic conditions (i.e., myocardial infarction, stroke, diabetes, cancer, pneumonia, etc.) was similar across country-income strata. Little research has been done in terms of economic prosperity and health in persons with intellectual disability. Recently, however, country economic status has been shown to be significantly associated with BMI (Body Mass Index) status of adult Special Olympics International (SOI) participants (Temple, Foley, \& Lloyd, 2015). Temple et al. (2015) found that lower economic prosperity was associated with relatively high levels of both underweight and overweight/obesity, while higher levels of prosperity were associated with high levels of overweight/obesity.
In summary, in the general population, hand grip strength is a strong predictor of health status, morbidity, and life expectancy; and grip strength is known to vary with country economic status. Further, among Special Olympics athletes, recent evidence illustrates that country economic status predicts a health outcome (i.e. BMI). However, to date, no studies have concurrently examined country economic status and hand grip strength among adults with intellectual disabilities. Therefore, the purpose of this study is to determine the extent at which country economic status is related to the muscular strength, as measured by hand grip strength, among adult SOI participants.

\section{Method}

\section{Data Source}

This study was a secondary analysis of grip strength scores of adult SOI participants by country economic status. Data were derived from the SOI FUNFitness database. For the present study, SOI provided participant: sex, age, event, location, delegation (world region and country), and grip strength scores for both right and left hands. Data for this database were collected during free health screenings by volunteer clinicians using established SOI protocols (Special Olympics, 2007) at local, state, national, and international SOI events during the period 2007-2012. A person is eligible to participate in the Special Olympics if he or she has an ID and is at least 8 years of age (Special Olympics, 2012). An individual is considered to have an ID for purposes of determining eligibility for Special Olympics if they meet any of the following requirements: (1) they have a cognitive delay as determined by standardized measures such as an IQ; (2) an agency or professional has determined the person has an ID in accordance with local policies; or (3) the person has functional limitations in both general learning (such as IQ) and in adaptive skills (Special Olympics, 2012). All participants in this study were Special Olympic participants.

Trained assessors (e.g. physiotherapists or physiotherapy students) are responsible for assessing handgrip during the FUNFitness assessments at Special Olympics events (American Physical Theray Association for Special Olympics Helathy Athletes, 2007). Athletes are instructed to sit straight up for the test. The test administer then demonstrates how the athlete must keep their body still, upper arm straight at their side, and their elbow must be bent 90 degrees while squeezing the hand-grip dynamometer. When the athlete was ready to begin, the test administer would 
say "ready, set, go" and instruct the athlete to, in one motion, squeeze for at least six seconds. Athletes are given three trials per hand, alternating between left and right, commencing with the dominant hand (established by asking which hand is used for eating or writing). The athlete's highest score for each hand is recorded. Furthermore, after data collection, athletes and family members had the option to meet with the qualified members of FUNFitness in order to go over their results. FUNFitness members provided feedback and recommendations to athletes on how to live a healthier life style (Special Olympics, 2013).

Participants' delegations were coded according to the World Bank's criterion for classifying economies (World Bank, 2012). The 127 countries within the SOI dataset were grouped by economy according to gross national income per capita (World Bank, 2012) as low-income countries $(n=11)$, lower middle-income countries $(n=27)$, upper middle-income countries $(n=38)$, and high-income countries $(n=51)$.

Athletes registered to participate in a Special Olympics games, and/or their guardians, sign a medical release/consent form (Special Olympics, 2007). This form includes consent for the de-identified data to be used for research purpose to report on the health of SOI athletes. Ethics approval for this secondary analysis was provided by the institutional ethics review committee of each author's university.

\section{Data Cleaning and Analyses}

Initially the database from SOI included 18,808 records of 18-65-year-old adults identified as athletes. Data cleaning procedures were as follows: first, identify multiple entries for one individual and delete duplicate or redundant entries $(n=2,747)$. This was done by filtering data by sex, birthday, country, and name. For individuals who had multiple entries in 1 year and/or entries over multiple years, the last entry for an individual was retained. Second, listwise deletions were used when, sex, age, economic status was missing, or when the individual was identified as a non-athlete $(n=754$ deleted). Third, the remaining data were examined and filtered to remove extreme values ( $n=3,175$ deleted). The values for inclusion were hand grip strength scores between $1.00 \mathrm{~kg}$ and the "Excellent" category (top 10th percentile of scores by age and sex) of the Canadian Society for Exercise Physiology (2004) reference data. Moreover, of the total sample used, 828 participants had values for only one arm (right hand only $n=399$; left hand only $n=529$ ). However, having at least one hand grip strength score (opposed to having both hand's scores) was deemed acceptable, taking into account the fact that some athletes may be missing an upper limb or have a non-functional limb.

To compare hand grip scores in adult SOI athletes by country economic status a one-way analysis of variance (ANOVA) was performed. Males and females were compared separately. Fisher-Hayter post hoc analyses were conducted on all possible pairwise contrasts. Data were analyzed using Stata/MP version 12 for windows (StataCorp LP, College Station, TX, USA).

\section{Results}

A total of 12,132 ranging in age from 18-65 years with an average age of 28 years and 8 months (men, $n=7,917$ ) adult SOI hand grip scores were available from 127 countries after data cleaning. Participant's mean hand grip scores as well as age are presented in Table 1. There was a significant overall effect of country's economic status for both males and females for right hand grip strength, $F(3,7614)=28.02$, $p<.001$ and $F(3,3981)=13.85, p<.001$, respectively. As well as left hand grip strength for both males $F(3,7670)=27.79, p<.001$ and females $F(3,4055)=13.30, p<.001$.

Table 2 shows the overall results of the FisherHayter post-hoc tests. This table shows that the grip strength of both men and women did not differ between low-income and low-middle income countries. For women from low-income countries, there was also no difference in grip strength compared to upper-middle income or upper-income countries. Outside of these null findings, the general trend was to observe greater grip strength with increased economic prosperity among both men and women, except when men upper middle-income countries were compared to men in upper-income countries, where the difference was the reverse. Men in upper-income countries had lower grip strength scores than men from upper middle-income countries.

\section{Discussion}

The findings show that country economic status was significantly associated with the hand grip scores of SOI participants. Overall, hand grip scores were generally higher among countries of higher economic prosperity. Males highest hand grip scores were in upper middle-income countries, whereas, females scores were highest in upper-income countries. These higher hand grip scores suggest that perhaps 
Table 1

Participant right and left hand grip score ( $\mathrm{kg}$ ) and age (years) by country economic status

\begin{tabular}{|c|c|c|c|c|c|c|c|c|c|c|c|c|}
\hline & \multicolumn{3}{|c|}{$\begin{array}{l}\text { Low-income } \\
\qquad(n=37)\end{array}$} & \multicolumn{3}{|c|}{$\begin{array}{l}\text { Lower middle-income } \\
\qquad(n=436)\end{array}$} & \multicolumn{3}{|c|}{$\begin{array}{l}\text { Upper middle-income } \\
\qquad(n=2504)\end{array}$} & \multicolumn{3}{|c|}{$\begin{array}{l}\text { Upper-income } \\
\qquad(n=9155)\end{array}$} \\
\hline & $\mathrm{M}$ & SD & $n$ & $\mathrm{M}$ & SD & $n$ & M & SD & $n$ & M & SD & $n$ \\
\hline \multicolumn{13}{|l|}{ Males } \\
\hline Right & 39.21 & 12.01 & 24 & 40.75 & 22.09 & 272 & 53.91 & 21.66 & 1690 & 50.46 & 24.56 & 5632 \\
\hline Age & 23.58 & 4.85 & 24 & 23.43 & 4.97 & 272 & 22.53 & 5.56 & 1690 & 30.49 & 10.55 & 5632 \\
\hline Left & 36.67 & 10.54 & 24 & 39.87 & 22.59 & 273 & 52.32 & 21.61 & 1715 & 48.62 & 24.13 & 5662 \\
\hline Age & 23.58 & 4.85 & 24 & 23.34 & 4.98 & 273 & 22.51 & 5.52 & 1715 & 30.48 & 10.52 & 5662 \\
\hline \multicolumn{13}{|c|}{ Females } \\
\hline Right & 32.08 & 7.76 & 13 & 27.60 & 13.97 & 152 & 32.10 & 13.10 & 743 & 34.43 & 15.36 & 3077 \\
\hline Age & 23.08 & 7.97 & 13 & 23.16 & 5.84 & 152 & 22.08 & 4.97 & 743 & 30.86 & 10.73 & 3077 \\
\hline Left & 32.15 & 7.80 & 13 & 25.99 & 14.12 & 150 & 31.30 & 13.25 & 756 & 33.17 & 15.29 & 3140 \\
\hline Age & 23.08 & 7.97 & 13 & 23.13 & 5.87 & 150 & 22.08 & 4.95 & 756 & 30.79 & 10.69 & 3140 \\
\hline
\end{tabular}

Note. $M=$ mean; $S D=$ standard deviation.

Table 2

Mean hand grip score difference (kg) from comparison of country economic status

\begin{tabular}{|c|c|c|c|c|}
\hline \multirow{2}{*}{ Comparisons } & \multicolumn{2}{|c|}{ Right } & \multicolumn{2}{|c|}{ Left } \\
\hline & Males & Females & Males & Females \\
\hline Low-income vs. lower middle-income & -1.54 & 4.48 & -3.20 & 6.16 \\
\hline Low-income vs. upper middle-income & $-14.71 *$ & -0.02 & $-15.65^{*}$ & 0.85 \\
\hline Low-income vs. upper-income & -11.25 & -2.35 & $-11.96^{*}$ & -1.01 \\
\hline Lower middle-income vs. upper middle-income & $-13.17 *$ & $-4.50 *$ & $-12.45^{*}$ & $-5.31 *$ \\
\hline Lower middle-income vs. upper-income & $-9.71 *$ & $-6.82 *$ & $-8.76^{*}$ & $-7.17 *$ \\
\hline Upper middle-income vs. upper-income & $3.45^{*}$ & $-2.33 *$ & $3.70^{*}$ & $-1.87^{*}$ \\
\hline
\end{tabular}

Note. Results presented are from the Fisher-Hayter pairwise comparisons, $*=p<.05$.

participants from high-income countries have more opportunities to develop their muscular strength. It is likely that lifestyle differences contribute to this variation in grip strength, particularly occupational/vocational engagement and leisure opportunities. Data from the World Health Organization Atlas on Global Resources for Persons with Intellectual Disabilities 2007 (Mercier, Saxena, Lecomte, Cumbrera, \& Harnois, 2008) show that levels of sheltered and supported employment, as well as general work training and development, were significantly higher with increasing country income status. For example, the proportion of adults with an intellectual disability receiving work skills training and/or development in low-income countries was $36 \%$ in 2007 , compared to $53 \%$ in low middle-income countries, $76 \%$ in upper middle-income countries, and $100 \%$ in high -income countries. As a majority of volunteer and paid employment performed by individuals with an intellectual disability is manual and these work activities increase physical activity levels compared to nonwork time (Temple, Rawlings, Crane, \& Stuart-Hill, 2016), it is likely that muscular strength is also being developed through participation in occupational and vocational activities. This proposition is supported by research showing higher levels of muscular strength among industrial workers compared to office workers (Chandra, Ghosh, Iqbal, \& Sadhu, 2007).

Mercier et al. (2008) also reported higher levels of leisure engagement with higher levels of economic prosperity. Fifty-six percent of individuals with an intellectual disability in low-income countries participated in leisure activities compared to $68 \%$ of in middle-income countries, and $100 \%$ of individuals with an intellectual disability in high-income countries. Although speculative, we suggest that 
lifestyle activities, rather than sport-specific training, are the likely source of the differences in grip strength seen in this study because all the participants in this study were participating in Special Olympics at the time of screening. A limitation of this study is that the individuals sport was not available, therefore we are unable to compare the grip strength of athletes competing in different events (e.g. power lifting vs. figure skating). Future research to explore the relative contribution of work, leisure, exercise and sport to the development of strength these is needed.

When the findings of the present study are compared to international grip strength norms for the general population (Massy-Westropp, Gill, Taylor, Bohannon, \& Hill, 2011; Norman, Stobäus, Gonzalez, Schulzke, \& Pirlich, 2011), it seems that male Special Olympians from low-income and lower middle-income countries have lower grip strength. Whereas the men from the upper middle-income and upper-income countries have grip strength values that are similar to the general population. In addition, the grip strength values for Special Olympics women in all income categories were similar to the general population (Massy-Westropp et al., 2011; Norman et al., 2011). However, like concerns raised regarding the general population (Norman et al., 2011), what level of grip strength is necessary to perform well in activities of daily living (e.g. work and recreation) and optimize health in young adult populations is unclear. However, it is also unknown why women with intellectual disability would have comparable grip strength scores on average compared to the general population of women while men did not. Future research should investigate whether vocational, recreational, sport, and domestic opportunities differ for men and women with intellectual disabilities in different regions of the world, why they might differ and what impact these opportunities have on grip strength and overall health.

Although clinically relevant values of grip strength have not been established for young adults with or without an intellectual disability, grip strength is a strong predictor for a number of negative future health outcomes (Gale et al., 2007; Leong et al., 2015; Newman et al., 2006; Ortega et al., 2012; Roberts et al., 2011). Thus, the findings of this study suggest that men with intellectual disabilities from lowincome and lower middle-income countries may be more at risk of adverse outcomes than other male Special Olympics participants.

A limitation of this study is that the economic status of the SOI participants in each country was not assessed. The relationship between economic status and hand grip strength may be evident between countries, but also within a country. Future studies should seek to explore further gradation of socioeconomic status of SOI participants. In addition to socioeconomic status, etiology and level of intellectual disability were not available from the SOI database. Finally, the sample of participants from low-income countries was small compared with the other country income categories in terms of total numbers and the countries represented and this study only included Special Olympics athletes.

\section{Perspective}

The extant literature is unclear about what levels of grip strength are relevant for health, work, activities of daily living, and participation in sports and recreation. To advance our knowledge of the importance of strength for these outcomes, research linking grip strength to health outcomes, functional status, and successful participation activities of daily living is needed. However, at the individual level, monitoring grip strength among Special Olympics athletes is important. Grip strength is a marker of overall upper extremity strength (Bohannon, 1998) and has been used to as a measure of health-related fitness (Tveter, Dagfinrud, Moseng, \& Holm, 2014) and to predict the onset of dependency in activities of daily living (Rantanen et al., 2002). Thus monitoring can flag unfavourable changes in strength, and prompt those who live and work with Special Olympics athletes to investigate why the individual's strength has decreased. Loss of muscle strength may result from a lack of opportunities to be physical active or it might be a sign of an inadequate diet, early aging, or an emerging medical condition (Carmeli, Imam, \& Merrick, 2012; Santilli, Bernetti, Mangone, \& Paoloni, 2014); and any of these explanations require follow-up and treatment or intervention.

\section{References}

American Physical Theray Association for Special Olympics Helathy Athletes. (2007). FUNfitness: Learn how to Organize, Promote and Present. Retrieved from http://www.specialolympics.org/uploadedFiles/LandingPage/WhatWeDo/ FUNfitness9-13-07.pdf

Bastiaanse, L. P., Hilgenkamp, T. I., Echteld, M. A., \& Evenhuis, H. M. (2012). Prevalence and associated factors of sarcopenia in older adults with intellectual disabilities. Research in Developmental Disabilities, 33(6), 2004-2012. doi: 10.1016/j.ridd.2012.06.002. 
Bohannon, R. W. (1998). Hand-grip dynamometry provides a valid indication of upper extremity strength impairment in home care patients. Journal of Hand Therapy, 11(4), 258-260. doi: 10.1016/S0894-1130(98)80021-5.

Brandon, L. J., Boyette, L. W., Gaasch, D. A., \& Lloyd, A. (2000). Effects of lower extremity strength training on functional mobility in older adults. Journal of Aging and Physical Activity, 8(3), 214-227. doi: 10.1123/japa.8.3.214.

Brill, P. A., Macera, C. A., Davis, D. R., Blair, S. N., \& Gordon, N. (2000). Muscular strength and physical function. Medicine and Science in Sports and Exercise, 32(2), 412-416. doi: 10.1097/00005768-200002000-00023.

Canadian Society for Exercise Physiology (2004). The Canadian Physical Activity, Fitness and Lifestyle Approach (3rd ed.). Ottawa, Canada: Canadian Society for Exercise Physiology.

Carmeli, E., Imam, B., \& Merrick, J. (2012). The relationship of pre-sarcopenia (low muscle mass) and sarcopenia (loss of muscle strength) with functional decline in individuals with intellectual disability (ID). Archives of Gerontology and Geriatrics, 55(1), 181-185. doi: 10.1016/j.archger.2011.06.032.

Caruso, L. B., Silliman, R. A., Demissie, S., Greenfield, S., \& Wagner, E. H. (2000). What can we do to improve physical function in older persons with Type 2 diabetes? Journal of Gerontology: Medical Sciences, 55(7), M372-M377.

Chandra, A. M., Ghosh, S., Iqbal, R., \& Sadhu, N. (2007). A comparative assessment of the impact of different occupations on workers' static musculoskeletal fitness. International Journal of Occupational Safety and Ergonomics, 13(3), 271-278. doi: 10.1080/10803548.2007.11076727.

Cuesta-Vargas, A., \& Hilgenkamp, T. (2015). Reference Values of Grip Strength Measured with a Jamar Dynamometer in 1526 Adults with Intellectual Disabilities and Compared to Adults without Intellectual Disability. PloS One, 10(6), e0129585. http://doi.org/10.1371/journal.pone.0129585

Evenhuis, H. M., Hermans, H., Hilgenkamp, T. I. M., Bastiaanse, L. P., \& Echteld, M. A. (2012). Frailty and disability in older adults with intellectual disabilities: Results from the healthy ageing and intellectual disability study. Journal of the American Geriatrics Society, 60(5), 934-938. http:// doi.org/10.1111/j.1532-5415.2012.03925.x

Faigenbaum, A. (2016). Assessment of muscular fitness. In E. Howley \& D. Thompson (Eds.) Fitness Professional's Handbook (7th Ed.) (pp. 179-194). Champaign, IL: Human Kinetics.

Fernhall, B., \& Pitetti, K. H. (2001). Limitations to physical work capacity in individuals with mental retardation. Clinical Exercise Physiology, 3, 176-185.

Gale, C. R., Martyn, C. N., Cooper, C., \& Sayer, A. A. (2007). Grip strength, body composition, and mortality. International Journal of Epidemiology, 36(1), 228-235. http://doi. org/10.1093/ije/dyl224.

Graham, A., \& Reid, A. (2000). Physical fitness of adults with an intellectual disability: A 13-year follow-up study. Research Quarterly for Exercise and Sport, 71, 152-16. http:// dx.doi.org/10.1080/02701367.2000.10608893.

Guadalupe-Grau, A., Carnicero, J. A., Gómez-Cabello, A., Gutiérrez Avila, G., Humanes, S., Alegre, L. M., ... GarcíaGarcía, F. J. (2015). Association of regional muscle strength with mortality and hospitalisation in older people. Age and Ageing, 44(5), 790-795. doi: 10.1093/ageing/afv080
Hilgenkamp, T. I., van Wijck, R., \& Evenhuis, H. M. (2012). Low physical fitness levels in older adults with ID: results of the HA-ID study. Research in Developmental Disabilities, 33(4), 1048-1058. doi: 10.1016/j.ridd.2012.01.013.

Hilgenkamp, T. I., van Wijck, R., \& Evenhuis, H. M. (2014). Subgroups associated with lower physical fitness in older adults with ID: Results of the HA-ID study. Research in Developmental Disabilities, 35(2), 439-447. doi: 10.1016/j.ridd.2013.11.015.

Kodama, S., Saito, K., Tanaka, S., Maki, M., Yachi, Y., Asumi, M., ... \& Yamada, N. (2009). Cardiorespiratory fitness as a quantitative predictor of all-cause mortality and cardiovascular events in healthy men and women: a meta-analysis. The Journal of the American Medical Association, 301(19), 2024-2035. doi: 10.1001/jama.2009.681.

Kuh, D., Bassey, E. J., Butterworth, S., Hardy, R., Wadsworth, M. E., \& Musculoskeletal Study Team. (2005). Grip strength, postural control, and functional leg power in a representative cohort of British men and women: associations with physical activity, health status, and socioeconomic conditions. The Journals of Gerontology Series A: Biological Sciences and Medical Sciences, 60(2), 224-231.

Leong, D. P., Teo, K. K., Rangarajan, S., Lopez-Jaramillo, P., Avezum, A., Orlandini, A., ... Yusuf, S. (2015). Prognostic value of grip strength: findings from the Prospective Urban Rural Epidemiology (PURE) study. The Lancet, 386(9990), 266-273. http://doi.org/10.1016/S0140-6736(14)62000-6.

Massy-Westropp, N. M., Gill, T. K., Taylor, A. W., Bohannon, R. W., \& Hill, C. L. (2011). Hand grip strength: Age and gender stratified normative data in a population-based study. $B M C$ Research Notes, 4(1), 127. doi: 10.1186/1756-0500-4-127.

Mercier, C., Saxena, S., Lecomte, J., Cumbrera, M. G., \& Harnois, G. (2008). WHO Atlas on global resources for persons with intellectual disabilities 2007: Key findings relevant for low- and middle-income countries. Journal of Policy and Practice in Intellectual Disabilities, 5(2), 81-88. doi: 10.1111/j.1741-1130.2008.00152.x.

Metter, E. J., Talbot, L. A., Schrager, M., \& Conwit, R. (2002). Skeletal muscle strength as a predictor of all-cause mortality in healthy men. The Journals of Gerontology Series A: Biological Sciences and Medical Sciences, 57(10), B359-B365. doi: 10.1093/gerona/57.10.

Newman, A. B., Kupelian, V., Visser, M., Simonsick, E. M., Goodpaster, B. H., Kritchevsky, S. B., ... \& Harris, T. B. (2006). Strength, but not muscle mass, is associated with mortality in the health, aging and body composition study cohort. The Journals of Gerontology Series A: Biological Sciences and Medical Sciences, 61(1), 72-77. doi: 10.1093/ gerona/61.1.72

Norman, K., Stobäus, N., Gonzalez, M. C., Schulzke, J., \& Pirlich, M. (2011). Hand grip strength: Outcome predictor and marker of nutritional status. Clinical Nutrition, 30(2), 135-142. doi: http://dx.doi.org/10.1016/j.clnu.2010.09.010.

Ortega, F. B., Silventoinen, K., Tynelius, P., \& Rasmussen, F. (2012). Muscular strength in male adolescents and premature death: cohort study of one million participants. British Medical Journal, 345, e7279. http://dx.doi.org/10.1136/bmj. e7279.

Pitetti, K. H., \& Yarmer, D. A. (2002). Lower body strength of children and adolescents with and without mild mental 
retardation: A comparison. Adapted Physical Activity Quarterly, 19(1), 68-81.

Pitetti, K. H., Yarmer, D. A., \& Fernhall, B. (2001). Cardiovascular fitness and body composition of youth with and without mental retardation. Adapted Physical Activity Quarterly, 18(2), 127-141. http://dx.doi.org/10.1123/apaq.18.2.127.

Rantanen, T., Avlund, K., Suominen, H., Schroll, M., Frändin, K., \& Pertti, E. (2002). Muscle strength as a predictor of onset of ADL dependence in people aged 75 years. Aging Clinical and Experimental Research, 14(3 Suppl), 10-15.

Roberts, H. C., Denison, H. J., Martin, H. J., Patel, H. P., Syddall, H., Cooper, C., \& Sayer, A. A. (2011). A review of the measurement of grip strength in clinical and epidemiological studies: Towards a standardised approach. Age and Ageing, 40(4), 423-429. http://doi.org/10.1093/ageing/ afr051.

Ruger, J. P., Jamison, D., \& Bloom, D. (2001). Health and the economy. In M. H. Merson, R. E. Black \& A. J. Mills (Eds.), International public health, diseases, programs, systems and policies (pp. 617-666). Gaithersburg, MD: Aspen.

Santilli, V., Bernetti, A., Mangone, M., \& Paoloni, M. (2014). Clinical definition of sarcopenia. Clinical Cases in Mineral and Bone Metabolism, 11(3), 177-180. doi: 10.1007/ s00223-013-9758-y.

Special Olympics Report. (2001). Hearing before a subcommittee of the Committee on Appropriations, United States Senate One Hundred Seventh Congress. Washington, DC: U. S. Government Printing Office.

Special Olympics. (2007). 2006 Reach Report. Washington, D.C.: Special Olympics.

Special Olympics. (2012). 2011 Reach Report. Washington, D.C.: Special Olympics.

Special Olympics. (2013). 2012 Reach Report. Washington, D.C.: Special Olympics.

Taggart, L., \& Cousins, W. (2013). Health promotion for people with intellectual and developmental disabilities. Maidenhead: McGraw-Hill Education.

Temple, V. A., Foley, J. T., \& Lloyd, M. (2015). Body Mass Index of Adult Special Olympians by Country Economic Status. Journal of Policy and Practice in Intellectual Disabilities, 1-9. http://doi.org/10.1111/jppi.12123.

Temple, V. A., Rawlings, K., Crane, J., \& Stuart-Hill, L. (2016). The contribution of work to daily physical activity among adults in supported employment. Journal of Intellectual Disability Research, 60, (parts 7 \& 8), 814.

Theou, O., Brothers, T. D., Rockwood, M. R., Haardt, D., Mitnitski, A., \& Rockwood, K. (2013). Exploring the relationship between national economic indicators and relative fitness and frailty in middle-aged and older Europeans. Age and Ageing, 42, 614-619. doi: 10.1093/ageing/aft010.

Tveter, A. T., Dagfinrud, H., Moseng, T., \& Holm, I. (2014). Measuring health-related physical fitness in physiotherapy practice: Reliability, validity, and feasibility of clinical field tests and a patient-reported measure. Journal of Orthopaedic \& Sports Physical Therapy, 44(3), 206-216. doi: 10.2519/ jospt.2014.5042.

World Bank. (2012). Country and lending groups. Retrieved from http://data.worldbank.org/about/country-classifications/ country-and-lending-groups\#Low_income

\section{Corresponding author}

Sara Santarossa

Email address | santaros@uwindsor.ca 